\title{
Research on the "Education, Competition, Research, and Cultivation" of the Four-in-One Dual-teacher Studio Education Model
}

\author{
Fang Li
}

Xi’an Peihua University, Xi’an, Shaanxi, 710125

Keywords: Four in One; dual-teacher; education mode

\begin{abstract}
In recent years, with the changes in the social employment environment, there has been a clear disconnect between college education and industry enterprises. The dual-teacher studio education model is continuously derived from the concept of "simultaneous theory and practice, equal emphasis on knowledge and technology". Based on the formation of college education teaching model, this paper focuses on "Education, Competition, Research and Cultivation" Four-in-One studio training model, to promote the school-enterprise cooperation and integration of production and education, and improve the overall quality of college students.
\end{abstract}

\section{Introduction}

Undergraduates are the cornerstone of the social talent system, and they are the accumulated power for the development of the country and society. They shoulder the important mission of promoting national culture, increasing the country's overall national strength, maintaining social harmony, and promoting economic prosperity and development. They are at the primary stage of socialism. The development of the path of socialism with Chinese characteristics cannot be separated from the assault of the main force of the undergraduates, and it is inseparable from the irresistible force of this powerful team [1]. Colleges and universities are important sources of cultivating and cultivating professional talents and skilled talents. In recent years, in order to improve the education level and overall quality of the people, major universities and colleges have been vigorously expanding their enrollment scales. The number of students has also increased year by year. It has become a force of talents that promotes social and economic development and overall national strength in China. However, at the same time, under the impetus of modern science and technology, the social employment environment and employment situation have undergone tremendous changes. The industry has been constantly optimized and upgraded. Early labor-intensive industries were gradually replaced by high-tech industries. The demand for human resources gradually evolved from manual labor to intellectual labor, and the need for talents gradually shifted to technical, practical and applied models. At the same time as the direction of extension, at the same time, emerging industries have sprouted and emerged, and more stringent requirements have been put on the innovative consciousness, innovation capability, and high-tech level of the employed talents [2]. Unit's need for increasingly diversified and comprehensive employment personnel, how to get rid of the teaching of higher education The dilemma of the derailment of teaching and social employment talent needs, closes the teaching content and occupational needs, allows the practical teaching to be close to the job standards, and allows the students to "follow the standard learning, in-depth training, and to enter the project, with the change of tasks". It is an important issue for higher education to learn, practice and integrate, improve the professional quality and employability of university graduates, and improve their employment competitiveness and employment quality.

\section{Dual-teacher Studio and Its Characteristics}

The dual-teacher studio teaching model is a college education teaching model that is continuously derived from the concept of "simultaneous theory and practice, equal emphasis on knowledge and technology". The studio of the double master was first born in the period of 
industrial development at the beginning of the last century and was in industrialization. In the period of rapid development, in order to meet the technical market's demand for talents and artistry, the Bauhaus School of Design in Germany has adapted to the needs of the times, transformed the philosophy of running schools and the mission of running schools, and aims to cultivate professional talents who can meet the requirements of industrial development and can quickly Invest in and participate in specific industrialization environments and positions, promote the continuous operation of industrialized gears, and also focus on cultivating students' artistic literacy, allowing students to practice artistic theories and art techniques that are closer to the actual social employment environment, and realize art and Handicrafts and the purpose of running a school under the contemporary industrialization environment, unified with the purpose of running a school [3]. In order to achieve this purpose of teaching and teaching objectives, the German Bauhaus Institute of Design creatively introduces a dual-teacher studio teaching model, which fully expands the diversification of its teaching staff, organically dismantles teaching content, and partially favors theoretical knowledge. The teaching content and teaching tasks of the class are borne by the original teachers of the school. The other part is biased towards the fact that the teaching content and teaching tasks of the artistic design practical and technical are handed over to the designers introduced by the school. Most of these designers come from social reality. The work environment, which has a very solid theoretical background and rich experience in art design work, allows students to be fully influenced by art theory knowledge and practical skills through such a dual mentoring studio, and cultivates both profound theoretical foundation and ownership. The practical ability that is in line with the current social employment has become the benchmark for applied art disciplines at that time, and it has profound implications for the construction of later-generation vocational education and applied teaching systems [4]. Affected by domestic political environment and other factors, China's higher education once suffered a fault and stagnated. Since the reform and opening up of the country to restore the college entrance examination system, China's higher education has gradually entered the development track and gradually exchanged and integrated with the international education environment. In terms of art and design majors teaching, China's early years still follow the traditional teaching model. The practicality of teaching content is weak. The teaching effectiveness cannot meet the needs of socio-economic development for artistic talents, and it faces the social employment environment for art and design talents. For practical needs, many teachers began to set up teachers' studios to train students' theory and practice. The studio teaching mode formed at this stage is mostly the teacher's spontaneous behavior, and the scale is relatively systematic and not systematic. Can get the attention of the entire art design education field. Until the 1980s, the college-level studios and dual-teacher studio mechanisms were gradually formed and promoted throughout the country. Through the strengthening of cooperation between universities and social enterprises in terms of the strength of teachers and teaching content, the importance of talent education in colleges and universities Practice links to improve the integration of college graduates' comprehensive ability and social employment environment. In 2014, the "Decision of the State Council on Accelerating the Development of Modern Vocational Education" fully affirmed the importance of dual-teacher studio teaching mode, and clearly emphasized that higher vocational colleges should pay attention to the construction of dual-teacher teachers and train dual-qualified teachers. Strengthen the integration of production, study and research, promote the integration of the teaching content of higher vocational colleges and the business modules of social enterprises, and vigorously build technical processes and product $R \& D$ centers to combine the scientific research achievements and talents of higher vocational colleges. Exported to industry enterprises, cooperated with enterprises to carry out technological innovation and industrial competitiveness improvement, the company's technical and management experience is exported to the actual teaching activities of higher vocational colleges, and to expand the vocational qualifications of higher vocational college students [5].

The dual-professional studio takes industry companies and colleges as the dual subjects of teaching. Based on the current and even future economic development needs of social talents, it integrates social professional talents in the faculty to expand the faculty resources of universities 
and promote the high-quality teaching activities in colleges and universities. The development has a very significant feature both in the innovation of the teaching model and in the improvement of the teaching system.

\subsection{Dual-teacher studios promote the deep integration of school, industry and enterprises}

Under the dual-professional studio teaching model, universities and industry enterprises are no longer independent of each other, and the relationship between universities and industry enterprises is no longer confined to the output and export outlets of graduates. Universities and industry companies are required to be able to use the studio as part of their own industry operations, to strengthen the sense of responsibility and ownership of the studio's operation and management of universities and enterprises, and to actively arrange the deployment of corresponding staff to participate in the construction of double studios. In actual teaching work, the production of industrial companies and scientific research in universities are effectively connected and linked through "learning." Students in dual-professional studios serve as bridges between universities and industrial enterprises, and can bring scientific research and technological achievements in colleges and universities to the forefront. To promote the innovation of its technological strength in industrial enterprises, it is also possible to bring the operational management modes of industrial enterprises and employment talents to colleges and universities to promote the reform of education and teaching methods in colleges and universities.

\section{2 "Education, competition, research and cultivation" enriches the function of dual-teach studios}

"Student productivity training, skills competition training, corporate project research and development and teacher skills training" is the latest functional orientation of the modern dual-professional studio, referred to as "study, match, research, and training". This functional positioning greatly expands the The studio's function and value break through the limitations of traditional dual-professional studios that focus on school-industry cooperation and teacher professional training. It also emphasizes the mutual benefit between students, teachers, schools, and industry and enterprises in the double-studio studio. With the model, students can introduce social production environment to a greater extent and improve their training level. Teachers can promote the professional construction and training of teachers through the expansion of teachers and the expansion of teachers' strength. The studio has introduced the scientific research and innovation achievements of colleges and universities as well as outstanding talent resources in universities. Colleges can improve the employment rate and employment competitiveness of colleges and universities through the quality training of students.

\section{The Practice of "Education, competition, research, cultivation" Four-in-One Training Mode}

The "four-in-one" dual-teacher studio education mode of "learning, competition, research, and training” is an important development direction of current art design colleges and many application-oriented professional education and teaching. Its constituent members are relatively complex and are no longer confined to the interior of colleges and universities. The management mechanism, but through the strengthening of school-enterprise cooperation, teacher-student cooperation in students, teachers, schools, industry and enterprises to form a mutually beneficial relationship between the benefits for students, teachers, universities and industry enterprises bring significant benefits.

\subsection{Construct the operating mechanism}

The "study, match, research, and cultivate" four-in-one dual-studio studio operation mechanism is the top-level design and key link for the formation and value development of the dual-professional studio. The operation and management of the dual-professional studio is inseparable from the support of the normative system. In order to ensure that the studios, teachers, 
students, and corporations can continuously benefit from the dual-professional studios, colleges and industrial companies, as the main bodies of studio operations management, should formulate studio operation management systems, for example, to maintain The teaching enthusiasm of teachers and social talents, universities and industry enterprises should set up a special teacher management supervision post on the basis of the overall overall planning group. On the one hand, it can effectively supervise the work of teaching staff in the studio and ensure its The successful completion of the teaching tasks and the expected effectiveness of teaching results can, on the one hand, also be responsible for planning and co-ordinating the teaching plan of the studio, coordinating the effective promotion of the teaching content of the studio, and fully guaranteeing the effectiveness of teaching work and social services of the studio. The implementation of functions. In addition, the dual-class studios should also establish a standardized personnel assessment mechanism, and should provide economic and policy incentives to teaching staff who can earnestly implement teaching and social service functions to stimulate the enthusiasm of teaching staff and ensure the full range of studio values. Realize and guide the work environment and collective work model of the dual-professional studio to develop in a healthy direction.

\subsection{School-enterprise cooperation and the integration of production and education}

The “Integrated Learning, Competition, Research, and Training” four-in-one dual-professional studio promotes the deep integration of college teaching with the production of industry companies by means of cooperation between schools and enterprises, providing students, teachers, universities, and enterprises with a relatively open and shared The learning and practice platform can give the students in the studio a more macro world view, perceive and explore the actual operation management mode of modern industry companies in advance, and their needs for talents, so as to help students identify learning objectives and work plans earlier. In terms of traditional single classroom teaching methods, this new type of learning and practice environment can inspire students' subjective initiative and learning enthusiasm, and strengthen their own training in professional skills and practical ability in projects and projects deployed by school-enterprise cooperation. To meet the needs of modern industry development for talent quality and practical ability. In terms of curriculum system construction, dual-professional studios should, on the basis of in-depth study of business modules and production operations of industry enterprises, combine relatively complete curriculum content with the syllabus of professional courses, and cooperate with the corresponding theoretical courses. Practical training courses allow students to apply theoretical knowledge to practice their professional skills after receiving theoretical knowledge; in the form of teaching organization, teachers and students can use organizational forms, and a teacher can be responsible for leading and guiding. 3-5 students, and based on project development to carry out education and teaching work, allowing students to explore the project process, project key issues, and core technologies from the perspective of real enterprise project practice environment, and further improve the quality of student training.

\subsection{The cultivation of dual-teacher and the expansion of faculty resources}

Teachers' power is an important factor in determining the teaching level and teaching quality of dual-professional studios. Based on the sustainable development of professional technology and vocational education, the "four-in-one" system is established with the carrier of "colleges, governments, vocational colleges, and industry enterprises". The team of faculty members integrates and optimizes teacher resources to improve the overall quality of the faculty. The main points of focus are: to improve the professional technical theoretical level of the faculty and the theoretical level of vocational education; to formulate a sustainable development mechanism for the faculty-team community, schools and government, occupational institutions Schools and industry enterprises actively explore collaborative development mechanisms to ensure the sustainable development of the teaching staff community; organize young teachers to vocational colleges to carry out teaching practices and improve the teaching and training abilities of vocational school teachers; establish a system of foreign advanced learning for middle and young backbone teachers, Gradually learn advanced teaching methods and education concepts from foreign advanced 
vocational education institutions; establish an encouragement system for excellent high-skilled personnel, cultivate high-skilled and outstanding key teachers; establish a training system for corporate trainers, and regularly organize enterprise trainers to teach related technologies in schools.

\section{Conclusion}

"Study, Competition, Research, and Cultivation" is a four-in-one, dual-professional studio in which colleges and industry companies operate as the studio's two main players, emphasizing the mutual benefit between students, teachers, schools, and industry and companies in the dual-professional studios. The model creates a more realistic social practice environment for students, which is conducive to improving the students' practical training level and teachers' professional skills, improving the transformation rate of scientific research achievements in universities, and helping to achieve the optimization and upgrading of industry enterprises.

\section{References}

[1] Cheng Zhang. Exploration of the "four-in-one" collaborative training model for "dual-qualified" teachers in new energy vehicles [J]. Talents, 2017(14):181-182.

[2] Zhu Laibin. Exploring the Four-in-One Cultivating Way of the "Double Teacher and Dual-energy" Teacher in Local Universities [J]. Journal of Fuqing Branch of Fujian Normal University, 2016(06):73-76.

[3] Jiang Xinge, Niu Dongyu. Research on the "Four-in-One" Dual-teacher Studio Cooperative Education Model of "Science Research and Training"[J]. China Vocational and Technical Education, 2016(26):44-48.

[4] WANG Zhen, TIAN Xing-qiang. Research on the construction mode of the "school-enterprise co-construction and co-construction type" productive practical training base--taking the construction of the "four-in-one production and practice training base" for machine-processing "production, education and research" in Guizhou Jiaotong Academy as an example [ J]. Education Teaching Forum, 2016 (33): 160-161.

[5] Duan Jinsuo. A study on the sustainable development model of the "two-teacher and dual-energy" teacher team based on the four-in-one system_—Based on the perspective of teacher professional growth[J]. Journal of Henan Institute of Animal Husbandry, 2016, 29(01): 75- 80. 